\title{
Fashion Customer's Purchase Intent Research Based on Natural Observation in Store
}

\author{
Wang Huan ${ }^{1} \&$ Lu Cheng ${ }^{1}$ \\ ${ }^{1}$ School of Fashion, Shanghai University of Engineering Science, Shanghai, China \\ Correspondence: Lu Cheng, School of Fashion, Shanghai University of Engineering Science, Shanghai 201620, \\ China. Tel: 86-139-1764-5127. E-mail: 1c@sues.edu.cn
}

Supported by Shanghai Municipal Education Commission Innovation Project “Consumer's Coordination Mechanism Research Based on Cross-channel Retail (A2-B-8901-13-0114)”,

Received: June 11, 2015 Accepted: July 3, $2015 \quad$ Online Published: July 5, 2015

doi:10.5430/sass.v2n2p28 URL: http://dx.doi.org/10.5430/sass.v2n2p28

\begin{abstract}
Using naturally observation investigation method, 72 groups of customers who are shopping in department store have been observed and analyzed. According to the data, the relationship between shopping actions and shopping result has high correlation. 5 kinds of shopping actions show correlativity with purchase result. Finally, 'IL-IT evaluation mode' is set out to measure consumer purchase intent.
\end{abstract}

Keywords: natural observation, garment, customer, purchase intent, evaluation

\section{Introduction}

Since the end of the twentieth century, many scholars had studied fashion consumer's behavior. One definition of consumer behavior is "The study of individuals, groups, or organizations and the processes they use to select, secure, use, and dispose of products, services, experiences, or ideas to satisfy needs and the impacts that these processes have on the consumer and society (Michael, Lu Taihong, \& Yang Xiaoyan, 2009).”

Questionnaire investigation was used as common way in this kind of research.Shopping actions are the most pivotal process in consumer behavior (Jeffrey, Eric, \& Peter, 2005). Fashion consumer, as a special consumer group, pays a lot of attention to shopping experience. Consumer gains first experience of brand and product in store, and decide purchase or not (Nicole, 2000). Since 1987, Paco Underhill has begun to observe consumer's shopping behavior using naturally observation method (Liang Lanzhi, 2005). He effectively develops the form of common consumable selling through investigation. This naturally observation investigation method means observing consumers who have no awareness to be involved in this investigation, so that consumers can act naturally (Parco, 2004). It's difficult to observe consumer's purchase intent directly. So consumer' shopping actions and purchase result are observed and analyzed to discuss the shopping actions which can be used to evaluate consumer's purchase intent.

\section{Fractionize Purchasing Actions}

According to normal action order in department store, fashion consumer's purchasing process is divided into 12 continuous actions, which are going into the store, touching garment, seeing tag, picking out size, trying on, talking with sales, looking into mirror, decision-making, paying, resting and leaving. Meanwhile, no all actions can be seen from one customer. The actions order can be different depending on different customers.

It is found in a pre-investigation that "picking out size" action cannot be an effective factor since it has the same frequencies with "trying on" action, so it is eliminated from the purchasing action factors. The "decision-making" action and "resting" action are also deleted because they can not be judged by exactly beginning time and end time. Then 5 actions show as major action factors in the pre-investigation, which are "Touch Garment", "Look at Tag", "Talk with sales", "Try on" and "Look into mirror". 
Purchase result is recorded as "Buy or not", "Purchase amount" and "Purchase money". In which, "Buy or not" is the most important criterion of purchase result.

\section{Experimental Procedure}

Shanghai Parkson Department Store and Shanghai Huijin Department Store are selected as investigation place, since the two stores are typical modern department store in shanghai. The second floor in Shanghai Parkson and the fifth floor in Shanghai Huijin has the same target consumer, with the same brands in, such as Jack\&Jones、ESPRIT、 TonyWear、Jockey、G2000、Richini etc. It provides an evidence that dada from the two stores has common character and also can be compared with each other.

The Investigation lasted five months. 72 fashion consumer cases are followed and recorded, with 153 people involved. Male consumers account for $52.9 \%$, and female consumers account for $47.1 \%$.

The effective sample in the disquisition is defined to be that the consumers enter into the store with fashion purchase intent.12 cases are found entering into the store with some other purpose instead of purchase intent. So they are deleted from the effective samples. There are finally 60 effective cases left. The effective sample rate is $83.3 \%$. The detailed number and proportion of effective samples are shown in table 1.

60 effective cases in department stores are followed and recorded, including all the shopping actions and purchase results in each store. The relationship between shopping actions and purchase result is analyzed in the following text.

Table 1. The distribution of fashion consumer samples

\begin{tabular}{llll}
\hline Sample Type & & Sample amount & Percentage \\
\hline \multirow{3}{*}{ Date Type } & Monday & 7 & 11.7 \\
& Wednesday & 14 & 23.3 \\
& Thursday & 6 & 10.0 \\
& Friday & 14 & 23.3 \\
& Saturday & 13 & 21.7 \\
& Sunday & 6 & 10.0 \\
\hline \multirow{3}{*}{ Weather } & Sunny & 41 & 68.3 \\
& Cloudy & 8 & 13.3 \\
& Cloudy with rain & 6 & 10.0 \\
Time & Heavy rain & 5 & 8.3 \\
\hline \multirow{2}{*}{ Place } & & samples basically evenly distribute from 09:30 to 21:00 & 16.7 \\
& Shanghai Huijin & 10 & 83.3 \\
\hline
\end{tabular}

\subsection{Factor Analysis of Shopping Behavior}

According to the dada of the investigation, total value, average and maximum values of five major action's frequency are respectively analyzed (see Table 2). Total value of five major actions reflects overall consumers' enthusiasm of shopping behavior. The average value of five major actions shows general level of consumers' actions. The maximum value of five major actions reflects the level of consumers' actions in their most interested store.

According to the frequency of five actions, they can be ranked from many to few as the following order: touching garment, seeing tag, talking with sales, looking into mirror, and trying on. This order accords with accustomed sequence of shopping actions exactly, and is in opposition to complexity sequence of those movements. 
Table 2. The frequency of consumer's shopping action factors

\begin{tabular}{lllllll}
\hline $\begin{array}{l}\text { Frequency of } \\
\text { Action in Different Stores }\end{array}$ & Amount & Min. & Max. & Average & $\begin{array}{l}\text { Standard } \\
\text { Deviation }\end{array}$ \\
\hline \multirow{4}{*}{ Average Action } & Louch Garment & 60 & 0.00 & 38.00 & 3.54 & 4.995 \\
Frequency & Talk with sales & 60 & 0.00 & 7.00 & 1.05 & 1.341 \\
& Try on & 60 & 0.00 & 8.00 & 0.29 & 1.064 \\
& Look into mirror & 60 & 0.00 & 6.00 & 0.30 & .836 \\
\hline \multirow{3}{*}{ Maximum } & Touch Garment & 60 & 0 & 38 & 7.40 & 7.488 \\
Action & Look at Tag & 60 & 0 & 13 & 2.68 & 3.281 \\
Frequency & Talk with sales & 60 & 0 & 10 & 1.73 & 2.490 \\
& Try on & 60 & 0 & 8 & 0.98 & 1.722 \\
& Look into mirror & 60 & 0 & 6 & 0.98 & 1.600 \\
\hline
\end{tabular}

\subsection{Consumers' Shopping Result}

It is known from the statistics that $30 \%$ consumers finally buy garment, of which $21.7 \%$ of consumers buy one piece of clothing, and $16.7 \%$ of consumers buy two pieces of clothing. Purchase amounts range from 128 Yuan to 1,958 Yuan. $16.7 \%$ of consumers spend less than 500 Yuan. 3.3\% of consumers spend $500 \sim 1000$ Yuan. $6.7 \%$ of consumers spend 1000 1500 Yuan. 3.3\% of consumers spend 1500 2000 Yuan.

\subsection{Correlation Analysis of Shopping Result Factor and Shopping Action Factors}

Pearson Correlation Analysis is analyzed to validate the affinity between consumer's purchase result and action factors.

Table 3. Pearson Correlation Analysis among purchase result and shopping actions

\begin{tabular}{|c|c|c|c|c|c|c|c|}
\hline \multicolumn{3}{|c|}{ Average Value of Shopping Actions in Stores } & $\begin{array}{l}\text { Touch } \\
\text { Garment }\end{array}$ & $\begin{array}{l}\text { Look at } \\
\text { Tag }\end{array}$ & $\begin{array}{l}\text { Talk with } \\
\text { sales }\end{array}$ & Try-on & $\begin{array}{l}\text { Look into } \\
\text { mirror }\end{array}$ \\
\hline \multirow[t]{2}{*}{ Purchase result } & $\begin{array}{l}\text { Pearson } \\
\text { coefficient }\end{array}$ & correlation & .206 & .474 & .369 & .105 & .133 \\
\hline & 2-tail-Significan & & .114 & .000 & .004 & .423 & .309 \\
\hline $\begin{array}{l}\text { Maximum } \mathrm{Va} \\
\text { Stores }\end{array}$ & le of Shopping & Actions in & $\begin{array}{l}\text { Touch } \\
\text { Garment }\end{array}$ & $\begin{array}{l}\text { Look at } \\
\text { Tag }\end{array}$ & $\begin{array}{l}\text { Talk with } \\
\text { sales }\end{array}$ & Try-on & $\begin{array}{l}\text { Look into } \\
\text { mirror }\end{array}$ \\
\hline \multirow[t]{2}{*}{ Purchase result } & $\begin{array}{l}\text { Pearson } \\
\text { coefficient }\end{array}$ & correlation & .494 & .656 & .601 & .496 & .534 \\
\hline & 2-tail-Significan & & .000 & .000 & .000 & .000 & .000 \\
\hline
\end{tabular}

It is shown from Table 3 that the Pearson correlation coefficients between Average Values of Shopping Actions in Stores and Purchase result are not all significant, while "Look at tag" and "Talk with sales" have high correlation with Purchase result. Meanwhile, the Pearson correlation coefficient between Maximum Values of Shopping Actions in Stores and Purchase result are all significant. It is explained that Maximum Values of Shopping Actions in Stores implies consumer's purchase intent in a store, because maximum value is generally happened in the store where consumer has the strongest purchase intent.

\section{Results and Discussion}

Consumer's purchase result is directly affected by purchase intent. So evaluating consumer's purchase intent should be one of the important marketing measures in store. Based upon the result of Pearson Correlation Analysis between 
purchase behavior and purchase, IL-IT evaluation mode is devised, and numerical values are offered as reference.

\subsection{IL-IT evaluation Mode}

Consumer's shopping actions in stores reflect the purchase intent. The five shopping actions correlative with purchase result are used to evaluate purchase intent in figure 1, which is called as IL-IT evaluation mode.

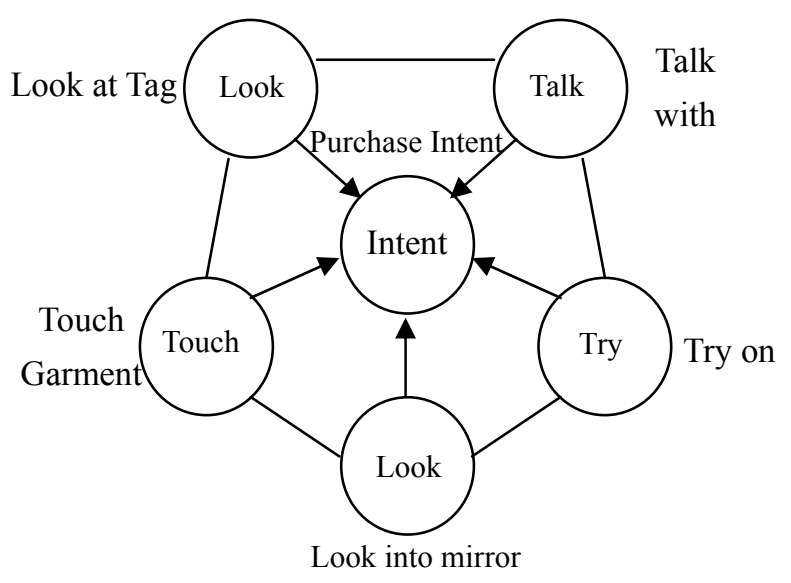

Figure 1. IL-IT evaluation mode

There are five important shopping actions around the consumer's purchase intent in figure 1, which are "Touch Garment", "Look at Tag", "Talk with sales", "Try on" and "Look into mirror".

Each shopping action can be observed in a store, more frequencies of shopping actions means more evidences of purchase intent. IL-IT evaluation mode is useful for sales in stores. But another important thing is that the sales should know how to serve customers well so that they can hold chances.

\subsection{Numerical Evaluation Reference of Fashion Purchase Intent}

According to the investigation, it's found that the highest customer actions' frequencies in a store are 38 times touching garment, 13 times looking at tag, 10 times talking with sales, 8 times trying on, and 6 times looking into mirror.

To make the evaluation easy doing, numerical reference standard is brought forward according to the investigation. If a consumer 13 times touching garment, 6 times looking at tag, 4 times talking with sales, 2 times trying on, and 2 times looking into mirror, that means that the consumer has so strong purchase intent that even want to buy.

\section{Conclusions}

Using naturally observation investigation method, consumer's repulsion can be avoided since they don't know they are involved with an investigation. The data are totally real and effective without consumer's pretend. The remarkable correlative between 5 shopping actions and purchase result is analyzed according to the investigation. IL-IT evaluation mode and numerical reference standard are brought forward. They can be used to evaluate consumer's purchase intent for sales in stores.

\section{Statement of Novelty}

Using naturally observation investigation method, 72 groups of customers who are shopping in department store have been observed and analyzed. According to the data, the relationship between shopping actions and shopping result has high correlation. 5 kinds of shopping actions show correlativity with purchase result. IL-IT evaluation mode and numerical reference standard are brought forward. They can be used to evaluate consumer's purchase intent for sales in stores. 


\section{References}

Business manager. (1996). Display based on product function, 28-30.

Brian J. Locky, \& Mark J. Smith. (1996). People's moving route in shopping center. City planning abroad, 2, 23-32. Chen Jianhui. (2005). Vision psychology on fashion store display and room arrangement. Zhuangshi, 151, 125-126.

China market inverstigate. (2005). investigation report on suit-dress distribution, 1-15.

Hu Xuyi. (2005). Fashion store design on digital time. International textile journal, 5, 67-72.

Jeffrey S. Larson, Eric T. Bradlow, \& Peter S. Fader. (2005). An Exploratory Look at Supermarket Shopping Paths. International Journal of Research in Marketing, 22, 103-133.

John Azcharias. (2002). Choosing a path in the underground visual information and preference. Acuus 2002 International Conference, 14, 144-145.

Liang Lanzhi. (2005). Observation on consumer shopping behavior research. Market investigate association, 1, 11-14.

Liu Li, \& Zhang Guolian. (2003). Fashion marketing investigation analysis—SPSS applications (pp. 163-178). China textile Publish Company, Beijing.

Lu Taihong, \& Huang Qining. Chinese shopping behavior. Distribution and market, 10-44.

Lu Yanhua. (2005). Fashion store system study based on modern marketing idea. Wipper, 1, 1-55.

Luo Ziming. (2000). Measurement guideline on consumer behavior. Beijing commercial college journal (social science edition), 15-30.

Ma Wen. (2000). Following consumer. Chinese Business, 10-11.

Michael. R. Solomon, Lu Taihong, \& Yang Xiaoyan. (2009). Consumer Behavior Buying, Having, and Being (Eight edition) (pp. 4-11). China Renmin University Press,Beijing.

Mu Ding. (2000). Shop arrangement design on chain store. Marketplace modernization, 7, 32-34.

Nicole Moye. (2000). Influence of Shopping Orientations. Selected Environmental Dimensions with Apparel Shopping, 1, 45-66.

Noi Sukaviriya, Mark Pldlaseck, Rick Kjeldsen, Anthony Levas, Gopal Pingali, Claudio Pinhanez. (2002). Embedding interactions in a retail store environment. The design and lessons learned, 10, 5-9.

Parco Underhill. (2004). The careful writer: Why we buy. Zhongxin publishing company, Beijing: 3-1.

Shanghai huiyan marketing consultant company. (2004). 2003 China investigation report on customers. Shopping behavior in supermarket, 1, 1-4.

Wang Qionghui. (2000). Human resource management demonstration on domestic sportswear retailer. Zhongshan human resource disquisition, 1, 1-25.

Wan Yanmin. (2006). Study on empolder fashion store design system. Donghua University Journal (natural science), 4, 74-79.

Winnie Daamen, \& Serge Hoogendoorn. (2004). Controlled experiments to derive walking behavior. European Journal, 4, 71-76.

Wu Hang. (1994). Constitution a microcosmic market investigation and statistic system. Lanzhou commercial college journal, 5-13.

Zhou Decai. (1997). Supermarket's plane arrangement. Changzhou technique teachers college journal, 2, 45-48. 